\title{
Egalitarian is a selective RNA-binding protein linking mRNA localization signals to the dynein motor
}

\author{
Martin Dienstbier, Florian Boehl, Xuan Li, and Simon L. Bullock ${ }^{1}$ \\ Cell Biology Division, MRC Laboratory of Molecular Biology, Cambridge CB2 0QH, United Kingdom
}

Cytoplasmic sorting of mRNAs by microtubule-based transport is widespread, yet very little is known at the molecular level about how specific transcripts are linked to motor complexes. In Drosophila, minus-end-directed transport of developmentally important transcripts by the dynein motor is mediated by seemingly divergent mRNA elements. Here we provide evidence that direct recognition of these mRNA localization signals is mediated by the Egalitarian (Egl) protein. Egl and the dynein cofactor Bicaudal-D (BicD) are the only proteins from embryonic extracts that are abundantly and specifically enriched on RNA localization signals from transcripts of gurken, hairy, K10, and the I factor retrotransposon. In vitro assays show that, despite lacking a canonical RNAbinding motif, Egl directly recognizes active localization elements. We also reveal a physical interaction between Egl and a conserved domain for cargo recruitment in BicD and present data suggesting that Egl participates selectively in BicD-mediated transport of mRNA in vivo. Our work leads to the first working model for a complete connection between minus-end-directed mRNA localization signals and microtubules and reveals molecular strategies that are likely to be of general relevance for cargo transport by dynein.

[Keywords: Drosophila; dynein; mRNA localization; microtubule-based transport; stem-loop]

Supplemental material is available at http://www.genesdev.org.

Received March 18, 2009; revised version accepted May 7, 2009.

Many proteins achieve an asymmetric localization within the cytoplasm through the transport of their mRNAs along the cytoskeleton by molecular motors (St Johnston 2005; Martin and Ephrussi 2009). Despite the widespread occurrence of mRNA transport, the detailed mechanisms by which specific transcripts are recognized and recruited to motor complexes are poorly understood. One exception is during bud-specific enrichment of mRNAs along actin filaments in the yeast Saccharomyces cerevisiae, where proteins have been identified that can account for a complete link between localizing mRNAs and the cytoskeleton (Gonsalvez et al. 2005). However, many metazoans rely on microtubules to deliver mRNAs over the requisite longer distances, and mechanistic insights into how these transcripts are linked to motors are relatively sparse.

One of the best prospects for elucidating microtubulebased mRNA transport is in the Drosophila syncytial blastoderm embryo, where a pathway for apical localization of a subset of endogenous mRNAs can be accessed by

${ }^{1}$ Corresponding author.

E-MAIL sbullock@mrc-lmb.cam.ac.uk; FAX 44-1223-412142.

Article published online ahead of print. Article and publication date are online at http://www.genesdev.org/cgi/doi/10.1101/gad.531009. microinjection of in vitro synthesized, fluorescently labeled transcripts (Wilkie and Davis 2001). Consistent with the nucleation of the minus ends of the microtubules in the apical cytoplasm, localization of these transcripts is driven by cytoplasmic dynein together with its accessory complex dynactin (Wilkie and Davis 2001). Related machinery delivers mRNAs to the minus ends of microtubules in other Drosophila cell types, including oocytes and neuroblasts (Bullock and Ish-Horowicz 2001; Hughes et al. 2004).

The cis-acting RNA elements mediating asymmetric localization by dynein have been studied in detail for seven transcripts (the developmentally important mRNAs bicoid [bcd], fushi tarazu [ftz], gurken [grk], hairy [h], $f_{s}(1) K 10[\mathrm{~K} 10]$, and wingless [wg], and the I Factor retrotransposon RNA) (Macdonald and Kerr 1998; Bullock et al. 2003; Cohen et al. 2005; Snee et al. 2005; Van De Bor et al. 2005; dos Santos et al. 2008) and contain one or more stem-loop structures. These "localization signals" are necessary for minus-end-directed localization and also sufficient when inserted into heterologous transcripts.

The localization signals in the different transcripts do not share significant primary sequence similarity and often have different lengths. This has led to two competing models (Van de Bor and Davis 2004): the first in which 
the RNA elements contain cryptic features that associate with a common recognition machinery, and the second in which they are recognized by different proteins, each able to independently provide a link to the dynein complex. It has not been possible to discriminate between these scenarios, because proteins that specifically bind any of these elements and are required for transport have not been identified.

In addition to dynein/dynactin, the Egalitarian (Egl) and Bicaudal-D (BicD) proteins are also essential for targeting of mRNAs to the minus ends of microtubules (Mach and Lehmann 1997; Bullock and Ish-Horowicz 2001; Bullock et al. 2004; Hughes et al. 2004; Claussen and Suter 2005). $\mathrm{Egl}$ and BicD are found in a complex with each other in vivo (together with other copies of themselves), although it is not known whether they interact directly (Mach and Lehmann 1997; Oh et al. 2000; Navarro et al. 2004). Egl and BicD also associate with dynein light chain (Dlc) and the dynein/dynactin complex, respectively (Hoogenraad et al. 2001; Navarro et al. 2004), and are recruited to injected localizing mRNAs in embryos to bias the net movements of a bidirectional mRNA transport complex apically (Bullock and Ish-Horowicz 2001; Bullock et al. 2006). Together, these observations have led to a model in which Egl and BicD associate with localization signals and increase the frequency of minus-end-directed dynein/ dynactin movements (Tekotte and Davis 2002; Bullock et al. 2006). Because neither Egl nor BicD has a known RNA-binding motif, it has been reasoned that they are recruited to localization signals by intermediary factors that directly contact the message (Pearson and GonzalezReyes 2004; Bullock et al. 2006).

Whether Egl has roles outside of mRNA transport has not been reported, but BicD functions in the transport of a subset of other cargoes for dynein (Swan et al. 1999; Matanis et al. 2002; Moorhead et al. 2007; Larsen et al. 2008). It has been proposed that the N-terminal twothirds of mammalian BicD are sufficient for stimulating dynein transport and that the remaining C-terminal sequences (hereafter referred to as the CTD [C-terminal domain]) mediate a link between cargoes and the motor (Hoogenraad et al. 2003). This is based on the findings that the CTD can be functionally substituted by heterologous motifs for organelle recognition (Hoogenraad et al. 2003) and can bind Rab6, a membrane-linked GTPase that recruits dynein to Golgi vesicles (Matanis et al. 2002; Short et al. 2002).

In this study, we attempt to elucidate the mechanism of linkage of different mRNA localization signals to dynein. We report the surprising finding that $\mathrm{Egl}$ is a selective RNA-binding protein that directly contacts active localization signals. Thus, seemingly divergent mRNA signals are recognized by the same factor. We also show that $\mathrm{Egl}$ associates with a conserved domain for cargo recruitment in BicD and is selectively required for mRNA transport in vivo. This work provides unique insights into the molecular links between localizing mRNAs and microtubule-based motors, and also sheds light on general mechanisms of cargo transport by dynein.

\section{Results}

A conserved role of the CTD of Drosophila BicD in recruiting cargoes to dynein

We were interested in whether the CTD of Drosophila BicD serves a similar function to the equivalent domain in the mammalian protein. We therefore mimicked the approach taken in mammalian cells (Hoogenraad et al. 2003) by testing regions of Drosophila BicD for their ability to promote minus-end-directed transport of heterologous cargoes in blastoderm embryos. Transgenic flies were generated expressing fusions of BicD sequences to the coat protein of the MS2 bacteriophage (Fig. 1A). The coat protein binds an MS2 stem-loop RNA with high affinity (Valegard et al. 1997), allowing transport activity of the BicD constructs to be assayed by monitoring the apical localization of fluorescently labeled MS2 RNA following injection.
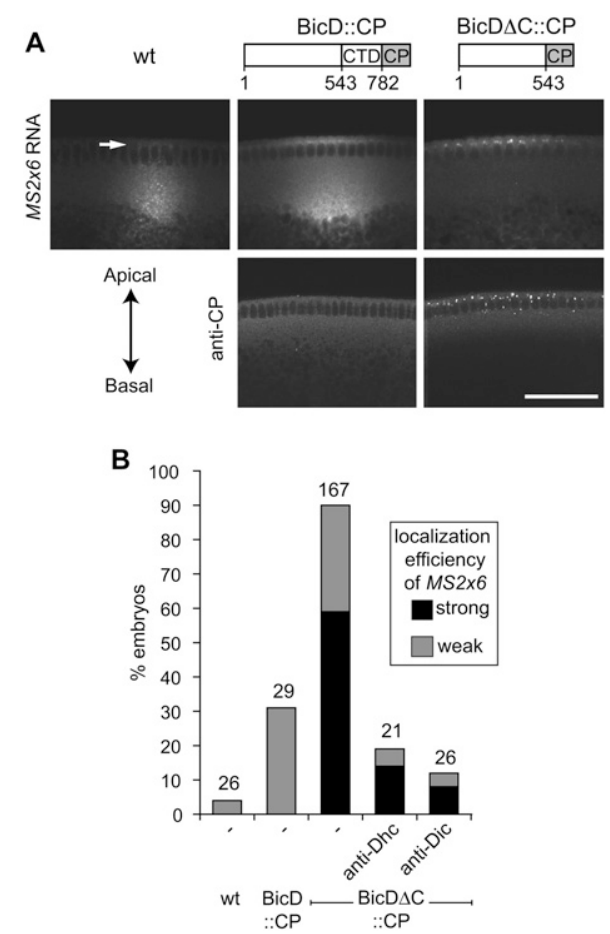

Figure 1. Removal of an inhibitory effect of the Drosophila BicD CTD is required for efficient transport of heterologous cargoes. (A) Images of syncytial blastoderm embryos of the indicated genotypes 10-14 min after injection with MS2x6 RNA (top panels) or following staining with anti-MS2 coat protein (CP) antibody (bottom panels; uninjected embryos). The apical cytoplasm (arrow) is a thin layer above the row of nuclei. (wt) Wild type (yw strain) in this and other figures. Bar, $50 \mu \mathrm{m}$. (B) Quantification of MS2x6 RNA localization efficiency. The top middle and top right panels in $A$ are representative examples of weak and strong localization, respectively. Embryos were injected with antibodies to dynein intermediate (Dic) or heavy chain (Dhc) 2-5 min before RNA injection as indicated, or just injected with RNA (-). Injection of buffer alone or control antibodies has no effect on RNA localization efficiency (Bullock and Ish-Horowicz 2001). 
As expected, a transcript containing six copies of the MS2 stem-loop (MS2x6) showed no significant asymmetric localization 10-14 min after injection into wild-type embryos (Fig. 1A,B). In contrast, MS2x6 RNA localized efficiently to the apical cytoplasm during this time in embryos expressing a fusion of the coat protein to a version of BicD (amino acids 1-543) lacking the CTD (BicD $\Delta \mathrm{C}:: \mathrm{CP}$ ). The mechanism of localization of MS2x6 RNA by this fusion protein was reminiscent of that exhibited by endogenous apical transcripts in wild-type embryos, being sensitive to preinjection of functionblocking antibodies to dynein subunits (Fig. 1B) (Wilkie and Davis 2001) and driven by rapid bidirectional movements with an overall bias in the minus-end direction (Supplemental Movie 1; Bullock et al. 2006; Vendra et al. 2007). Thus, in flies, as in mammals (Hoogenraad et al. 2003), the role of the BicD CTD in dynein transport can be functionally substituted by a heterologous recognition motif. This demonstrates that the CTD could ordinarily function in recruitment of cargo. Compatible with such a notion, the interaction of the BicD CTD and Rab6 is conserved in Drosophila (Fig. 2A; Coutelis and Ephrussi 2007; Januschke et al. 2007).

In contrast to a $\triangle \mathrm{CTD}$ construct, full-length BicD does not promote efficient minus-end-directed transport of tethered cargoes in cultured mammalian cells (Hoogenraad et al. 2003). Thus, the CTD has an inhibitory role in the context of the intact mammalian molecule. This also appears to be the case for the Drosophila protein, because only very weak apical localization of MS2x6 RNA was observed in embryos expressing the full-length fly BicD (amino acids 1-782) fused to the coat protein (BicD::CP) (Fig. 1A,B). Consistent with the above data, in uninjected embryos BicD $\Delta \mathrm{C}: \mathrm{CP}$ protein was enriched apically in particles (see the Discussion), and BicD::CP had a uniform apico-basal distribution (Fig. 1A). We also found that a physical interaction between the CTD and $\mathrm{N}$-terminal BicD sequences in mammals (Hoogenraad et al. 2001) is conserved in flies (Supplemental Table 1).

Collectively, our observations in Drosophila fit with a previous proposal for the mode of BicD regulation in mammals (Hoogenraad et al. 2003) in which the interaction of the CTD with N-terminal BicD sequences holds the protein in an inactive confirmation in the absence of cargo. Association of a cargo-binding protein with the CTD presumably competes out the self-interaction, freeing the $\mathrm{N}$ terminus to stimulate cargo transport by dynein. Later, we describe the use of the MS2 tethering assay to further dissect BicD function during the activation of transport.

\section{Egl binds the CTD of BicD in vitro and in vivo}

The apparent conservation of BicD regulation in flies and mammals suggested that the unidentified protein(s) that contacts Drosophila apical RNA elements is linked to BicD via the CTD (amino acids 544-782). However, it is unlikely that the CTD-binding protein Rab6 plays a role in recognizing localizing mRNAs, because strong hypomorphic rab6 embryos ( $\mathrm{rab6}^{\text {eam4 }} / \mathrm{rab6}^{\text {ex23D}}$ ) (Purcell and
Artavanis-Tsakonas 1999) showed no alteration in the efficiency of apical transport of injected $h, f t z$, or runt mRNAs in blastoderm embryos (strong apical localization in $85 \%-95 \%$ of wild-type and rab6 embryos $8-12$ min after injection $(n>20)$.

In a related project, we found 44 clones of BicD in a yeast two-hybrid screen for Drosophila proteins interacting with full-length Egl (amino acids 1-1004 [Q7YU43]). Truncated clones found in the screen (see the Materials and Methods) identified an Egl-binding region of BicD within the CTD (amino acids 647-782), and this was confirmed by the ability of in vitro translated Egl to be pulled down with a recombinant GST-CTD fusion protein, but not GST alone (Fig. 2B). Yeast twohybrid experiments also demonstrated that Egl binds fulllength BicD, but not BicD 1-543, which lacks the CTD (Supplemental Table 1). These data show for the first time that Egl and BicD can bind directly and that the CTD of BicD is both necessary and sufficient for the interaction.

The smallest region of Egl tested that binds the CTD was amino acids $1-79$ (Fig. 2A,B). The importance of this region in binding $\mathrm{BicD}$ is underscored by the discovery in a genetic screen of a substitution at residue 35 (C $\rightarrow$ Y; in the strong egl loss-of-function allele $4 e$ ) that blocks coimmunoprecipitation of $\mathrm{Egl}$ and BicD in vivo (Navarro et al. 2004), and that we confirmed inhibits direct binding of the two proteins in vitro (Fig. 2B).

Forward genetics has also identified an amino acid substitution in the CTD-K730M-that abrogates BicD function in the fly (Ran et al. 1994). K730 is evolutionarily conserved in invertebrate and vertebrate BicDs (Supplemental Fig. 1A) and is predicted to reside within a coiledcoil domain contained within the CTD (Hoogenraad et al. 2001). We found that the K730M substitution inhibited binding of BicD to Egl in the yeast two-hybrid and in vitro pull-down assays (Fig. 2A,B). However, the mutation did not prevent the CTD from interacting with other copies of BicD (Fig. 2A), implying that it does not have a general effect on BicD stability or folding. Immunoprecipitation experiments revealed that transgenically expressed, GFPtagged BicD formed a stable complex with Egl in Drosophila ovary extracts, whereas the equivalent K730M construct did not (Fig. 2C). This result corroborates in vivo the specificity of the yeast two-hybrid and in vitro pull-down experiments, which demonstrate that Egl binds directly within the CTD of BicD.

\section{Egl function in BicD-mediated transport is selective for RNA cargoes}

As described in the introduction, binding of Rab6 to the BicD CTD provides a link between vesicular cargoes and dynein. We found that binding of Rab6 to the CTD was abolished by the K730M substitution (Fig. 2A). This implies that Egl and Rab6 bind similar features on BicD, and raises the possibility that $\mathrm{BicD}$ executes its role in transport of different cargoes by mutually exclusive association with different adaptor proteins.

To test this notion in vivo, we investigated the relative roles of Egl and BicD in the bidirectional transport of lipid 
A

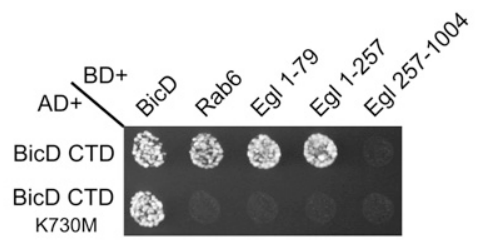

B

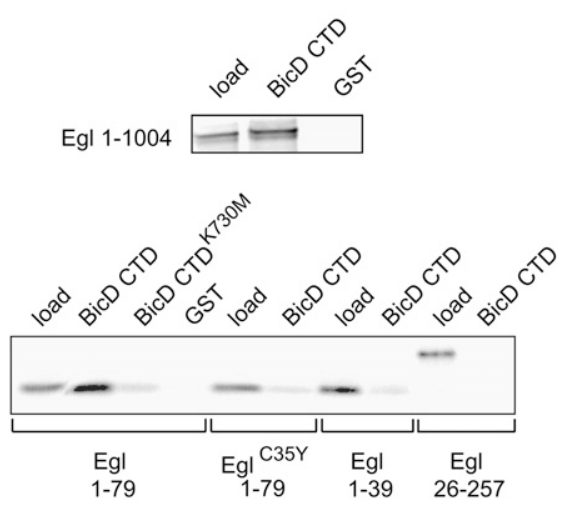

$\mathbf{F}$

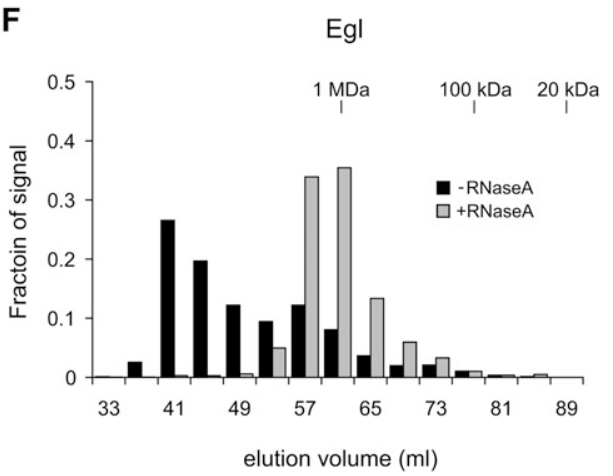

C

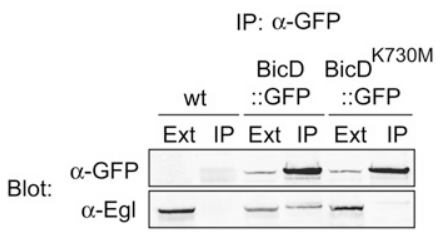

D

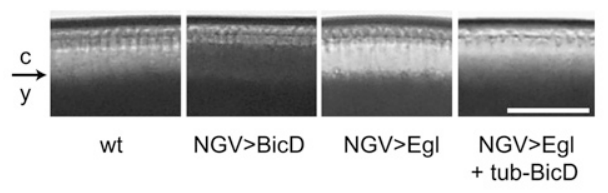

E
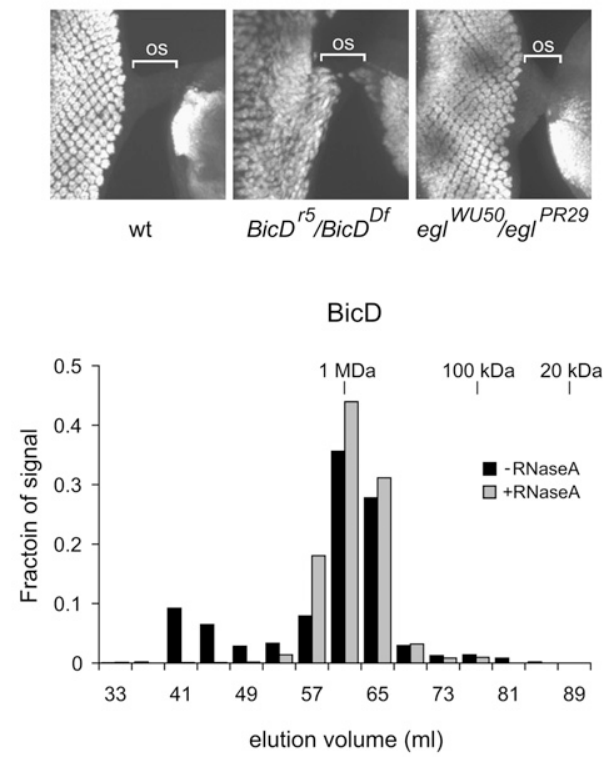

Figure 2. Egl interacts directly with the BicD CTD through amino acids 1-79 and does not have a general function in BicD-mediated transport. (A) Yeast two-hybrid assays of interactions of the BicD CTD with full-length BicD, Rab6, and Egl. AD and BD, fusion to GAL4 activation, and DNA-binding domains, respectively. Interactions reconstitute the expression of Ade and His and result in growth of colonies on selective plates. The interactions between Egl and BicD were also confirmed by swapping the identity of the proteins in the $\mathrm{AD}$ and BD vectors (see Supplemental Table 1 for these and other interactions assayed). (B) Assessment of the binding of in vitro translated ${ }^{35}$ S-methionine-labeled Egl fragments to the BicD CTD, fused to GST, or GST alone (GST). Radioactive Egl signals are shown. Load represents $10 \%$ of that used in each pull-down assay. $(C)$ Egl is coimmunoprecipitated with BicD::GFP, but not BicD ${ }^{\mathrm{K} 730 \mathrm{M}}:: \mathrm{GFP}$, from transgenic ovary extracts (using $\alpha$-GFP). Load represents $2 \%$ of that used in each immunoprecipitation assay. $(D)$ UAS-driven overexpression of BicD (with the GAL4VP16 ${ }^{\text {nos }}$ driver [NGV]) prevents basal redistribution of lipid droplets, leading to an opaque cytoplasm. Overexpression of Egl leads to excessive basal movement and an almost transparent cytoplasm. Nile red staining of neutral lipids confirmed that this is due to a redistribution of droplets and not a gross change in the amount of droplets in the embryo (data not shown). The effect on Egl overexpression is suppressed by mild overexpression of full-length BicD (tub-BicD::CP). Arrow marks the junction of the yolk (y) and cytoplasm (c) in the blastoderm embryo. Supplemental Figure 1B shows protein levels in the different scenarios. (E) Nuclei (marked by Elav) are mislocalized in the optic stalk (os) and have an irregular apico-basal distribution in the retina (left) in third instar mutants for BicD, but not egl. Zygotic mutant genotypes are shown; no maternal or zygotic Egl and BicD protein could be detected in the respective mutants at this stage of development (X Li and S Bullock, in prep.). Bars: $D, 50 \mu \mathrm{m} ; E, 35 \mu \mathrm{m}$. (F) Gel filtration of wild-type embryo extract in the presence or absence of RNaseA. Data shown are fractions of total Western blot signals for Egl or BicD from individual 4-mL fractions. Numbers on the top correspond to molecular weight of globular protein standards extrapolated from column calibration. We determined that the gel filtration profile of a control protein ( $\alpha$-tubulin) was not altered by RNaseA treatment (data not shown). The majority of $\mathrm{Egl}$, but $<20 \%$ of $\mathrm{BicD}$, is present in a relatively high-molecular-weight complex whose size is sensitive to RNaseA treatment.

droplets in the Drosophila blastoderm embryo. Lipid droplets are initially distributed uniformly, undergoing bidirectional transport with little net bias and are shifted basally during nuclear cycle 14 by an increase in the relative time spent moving toward the plus ends of the microtubules (Welte et al. 1998). BicD is present on lipid droplets, and partial loss-of-function studies show that it contributes predominantly to the dynein-dependent apical component of motion at blastoderm stages (Larsen et al. 2008). Consistent with these findings, we found that 
BicD overexpression prevented the transition of droplets to net basal movement (Fig. 2D).

Overexpression of Egl or BicD significantly increases the frequency of minus-end movement of mRNAs in the blastoderm embryo (Bullock et al. 2006). If Egl were a general cofactor for BicD, one would predict that increasing its concentration would have a similar effect on lipid droplet distribution to overexpressing BicD. Alternatively, if Egl functions only in the transport of specific cargoes, such as mRNA, its overexpression might be able to divert BicD from droplets and lead to the opposite effect to elevating BicD levels. Our observations support the second scenario; approximately threefold overexpression of Egl (Supplemental Fig. 1B) resulted in excessive enrichment of the lipid droplet population basally (Fig. 2D). Mild overexpression of BicD (Supplemental Fig. 1B) suppressed the Egl-induced basal displacement of droplets (Fig. 2D), consistent with elevated levels of Egl altering droplet distribution by sequestering BicD. These findings indicate that Egl does not cooperate with BicD in lipid droplet transport.

BicD's role in positioning of another cargo is also independent of Egl. Third instar larvae mutant for BicD have nuclei mislocalized in the optic stalk (Fig. 2E) and in the retina (Swan et al. 1999), as do mutants for a dynactin subunit (Whited et al. 2004). In contrast, larvae lacking Egl protein have no such defects (Fig. 2E). Collectively, these results are compatible with Egl's role in BicDmediated transport processes being restricted to mRNA cargoes. In support of this notion, size-exclusion chromatography of embryonic extracts revealed that the majority of Egl, but only a small fraction of BicD, is present in complexes whose size is sensitive to RNase treatment (Fig. 2F).

Egl and BicD are the only detectable factors specifically captured from Drosophila embryonic extracts by several $m R N A$ localization signals

The results presented so far pointed toward a selective role of Egl in connecting RNA localization signals to the BicD CTD and, therefore, dynein. Because Egl does not contain a canonical RNA-binding motif, we anticipated that additional proteins would mediate Egl recruitment to RNA, possibly with different Egl-associated proteins being dedicated to different transcripts. To attempt to identify the RNA recognition machinery, we optimized an affinity purification protocol in which Egl was specifically enriched on localizing RNAs and searched for copurifying factors (Bullock et al. 2006; see the Materials and Methods). Briefly, we fused minimal localization signals, as well as nonlocalizing variants, to an RNA aptamer selected to bind streptavidin with high affinity (Srisawat and Engelke 2001). These fusion transcripts were immobilized to a streptavidin matrix and used to capture proteins from embryonic extracts, followed by extensive washing and elution with biotin.

We generated aptamer fusions to minimal dyneindependent localization signals from $K 10$ (TLS), the I Factor retrotransposon $(I L S)$, grk $(G L S)$, and $h(S L 1)$ (Supplemental
Fig. 2; Bullock et al. 2003; Cohen et al. 2005; Van De Bor et al. 2005). These elements were selected because they comprise a single, relatively short stem-loop. By injecting fluorescent RNA into embryos we determined that each of the minimal wild-type elements drives apical transcript enrichment in the context of the aptamer fusion (Fig. 3A). The localization driven by $h S L 1$ was, however, weaker than that driven by the other elements (Fig. 3A), consistent with efficient localization of full-length $h$ being contingent on another natural $h$ stem-loop or artificial dimerization of hSL1 (Bullock et al. 2003).

The first type of nonlocalizing control transcript comprised fusions of the aptamers to minimal localization signals containing subtle mutations that prevent apical accumulation in the embryo injection assay within the context of the full 3' untranslated region (UTR) ( $h S L 1^{\text {C15G }}$ [d22] [Bullock et al. 2003]; TLS $S^{\Delta b u b}$ and TLS ${ }^{U 6 C}$ [SL Bullock, I Ringel, D Ish-Horowicz, and P Lukavsky, in prep.]), while having little effect on predicted secondary structure (Supplemental Fig. 2). The aptamer was also fused to antisense localization signals, which are predicted to form stem-loops of similar size, thermodynamic stability, and base composition to the respective wild-type elements, but contain several minor changes to the secondary structure (Supplemental Fig. 2). All of the mutated and antisense RNA sequences lacked detectable apical localization activity in vivo in the context of the aptamer fusion (Fig. 3A).

In the first instance, we searched for proteins from extracts associated preferentially with the wild-type $K 10$ $T L S$ relative to an antisense $K 10$ element $\left(T L S^{a s}\right)$. We reproducibly detected only two proteins stably enriched on the former relative to the latter, and these were associated with RNA in an $\sim 1: 1$ ratio (Fig. $3 \mathrm{~B}$, bands $\mathrm{a}$ and $\mathrm{b})$. Unexpectedly, these proteins were unambiguously identified by mass spectrometry as Egl and BicD, respectively (30 unique peptides for Egl; 21 for BicD) and their identity was also verified by Western blotting (Fig. $\left.3 \mathrm{~B}^{\prime}, \mathrm{C}, \mathrm{E}\right)$ and using Egl-GFP extracts (Fig. 3B, band e). We also confirmed that the recruitment of Egl and BicD to the TLS was inhibited by the other mutations that inhibit apical localization activity $(\Delta b u b$ and $U 6 C)$ (Fig. 3C,E).

Our findings demonstrate that Egl and BicD are the major proteins purified from extracts that preferentially associate with the active K10 TLS. To test whether this might also be the case for other signals that mediate minus-end-directed transport, we repeated the affinity purification procedure with the remainder of the localizing and nonlocalizing aptamer fusions. Egl and BicD were also the only detectable factors reproducibly enriched on localizing versions of the grk, I Factor, and $h$ elements relative to any of the corresponding nonlocalizing controls (Fig. 3D, $\mathrm{D}^{\prime}, \mathrm{E}$ ), and were again present in an $\sim 1: 1$ ratio (Fig. $3 \mathrm{D}$ ). Thus, these two proteins appear to be the only factors from embryonic extracts that exhibit preferential recruitment to active localization signals from a variety of transcripts. This observation suggests that mRNA signals in multiple transcripts are directly contacted by Egl, BicD, or by both proteins. 
A
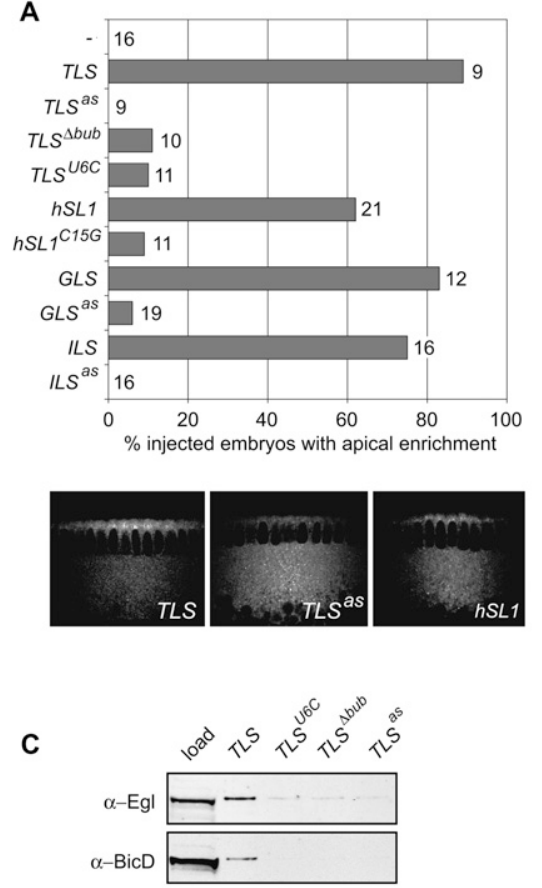

E

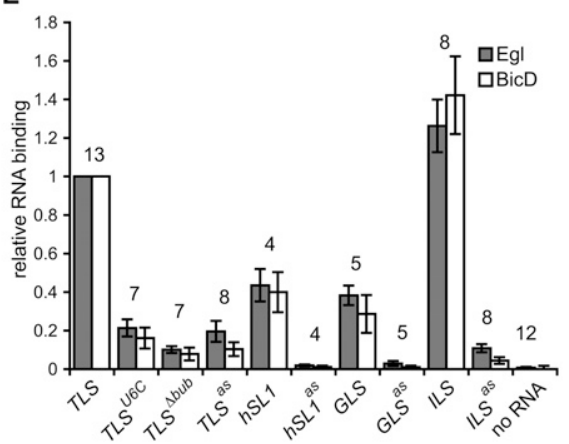

B
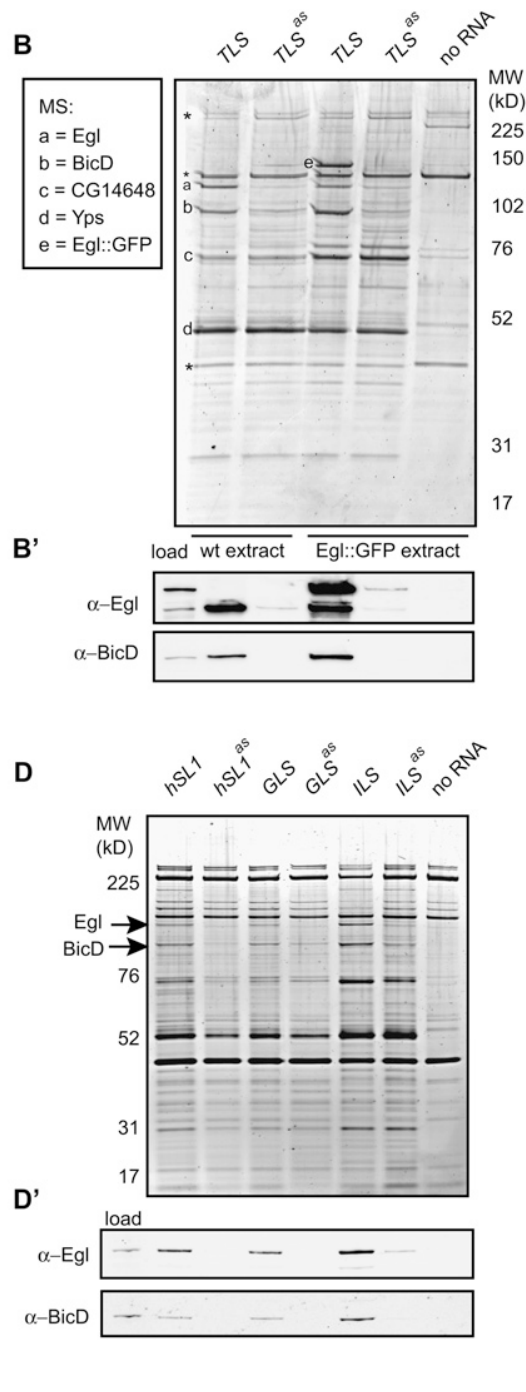

Figure 3. Egl and BicD are the only detectable factors stably and specifically enriched from embryonic extracts on active minus-end-directed localization signals. (A) Quantification of apical localization activity of wild-type and mutant localization elements in the context of fusion to the streptavidin aptamer. Total number of embryos scored for each RNA is shown. (as) Antisense; (-) aptamer alone. Representative images of embryos injected with localizing and nonlocalizing fusion transcripts are shown below. (B) Sypro Ruby stained gel showing detectable enrichment of only Egl and BicD from embryonic extracts on the wild-type K10 TLS compared with on an antisense TLS (MS, mass spectrometry IDs). The RNA-binding proteins Yps and CG14648, as well as proteins that bind the streptavidin matrix (asterisks), are present in similar amounts in experiments with wild-type and mutant elements. Yps (Mansfield et al. 2002) and CG14648 (S Bullock, unpubl.) do not appear to participate in Egl and BicD-dependent mRNA transport in vivo and are therefore likely to be nonspecific RNAbinding factors. Conducting the experiment with extracts that express Egl::GFP in addition to endogenous Egl confirms the identity of Egl as one of the factors specifically retained on localizing elements. $\left(B^{\prime}\right)$ Western blot of samples in $B$ confirming the identity of Egl and BicD as the proteins enriched preferentially on active TLS elements. Load lane is from Egl::GFP extracts and represents $2 \%$ of input into RNAbinding assays. Additional TLS mutants are shown in $C$. $(D)$ Silver-stained gel showing that $\mathrm{Egl}$ and $\mathrm{BicD}$ are also the only factors visibly and reproducibly enriched from wild-type embryonic extracts on minimal localizing signals from $h$ (hSL1), grk (GLS), and I factor (ILS) relative to nonlocalizing controls. Although some additional differential bands are seen on $h S L 1$ and GLS relative to controls, these were not reproducible. Western blots are shown in $D^{\prime}$. (E) Quantification of relative amounts of Egl and BicD captured from wild-type embryonic extracts on RNAs as indicated. Data are quantified from fluorescent Western blot signals normalized to the wild-type TLS. The number above the bars is the number of independent experiments. Error bars represent SEM.

\section{Egl binds RNA in vitro, and preferentially associates with active localization elements}

We next tested whether either recombinant Egl or BicD has the capacity to bind RNA in vitro. We first synthesized small amounts of proteins using coupled transcription and translation in rabbit reticulocyte lysates and tested their ability to associate with aptamer-fused active and inactive localization signals tethered to a streptavidin matrix. We did not detect binding of full-length $\mathrm{BicD}$, $\operatorname{BicD} \Delta \mathrm{C}$, or BicD CTD, as well as a control protein (Dlc), to any of the RNAs (Fig. 4A). However, in vitro translated Egl protein bound all RNAs tested, with significantly more retained on representative wild-type elements relative to matched nonlocalizing controls $(\sim 2.5$-fold to threefold greater binding to $T L S$ vs. $T L S^{a s}, T L S^{\Delta b u b}$, and
$T L S^{U 6 C}$ and approximately sixfold greater binding to $I L S$ vs. $\left.I L S^{a s}\right)$ (Fig. 4B,C).

We purified recombinant Egl following overexpression in S. cerevisiae (Supplemental Fig. 3A) and found that it too associated with RNA. However, unlike in vitro translated Egl, this preparation could not discriminate between active and inactive elements (Fig. 4D; Supplemental Fig. 3B). In contrast, a heteromeric complex of Egl together with BicD (coexpressed in yeast and purified using an affinity tag on Egl [Supplemental Fig. 3A]) bound preferentially to the wild-type signals (TLS, ILS, and GLS) relative to nonlocalizing controls $\left(T L S^{U 6 C}, T L S^{a s}, I L S^{a s}\right.$, and $G L S^{a s}$ ) in the streptavidin-based assay (Fig. $4 \mathrm{D}, \mathrm{E}$ ). As was the case for in vitro translated Egl, the difference in binding of the Egl-BicD complex to localizing RNAs relative to control sequences was quite modest, but 
Dienstbier et al.

A

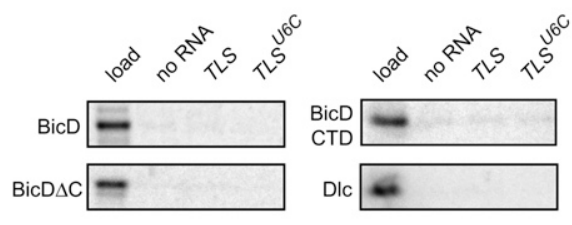

B

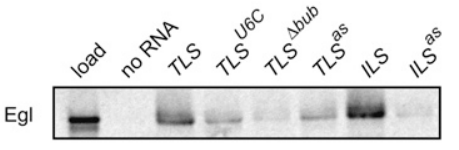

C

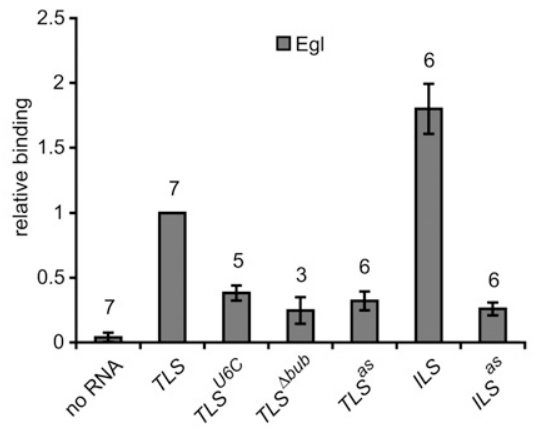

$\mathbf{F}$

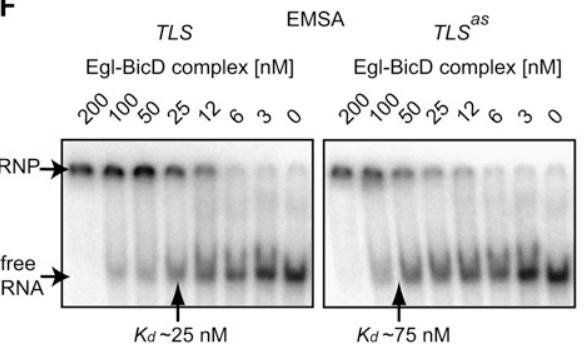

D

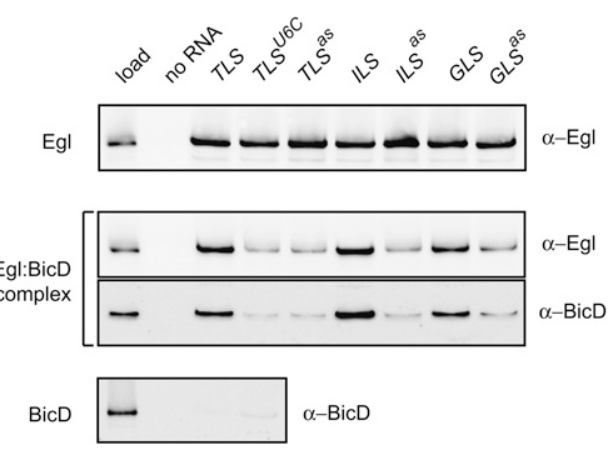

E

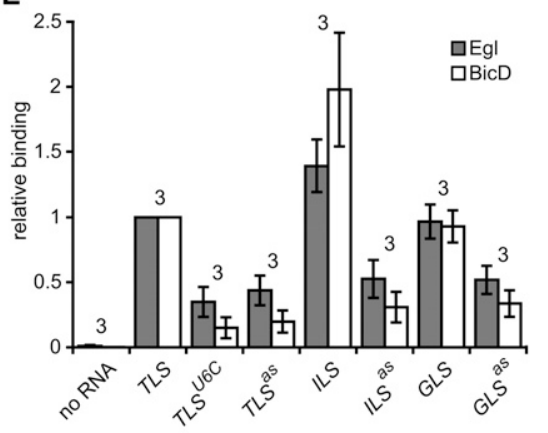

G

EMSA competition

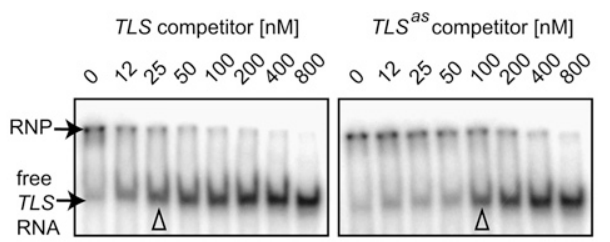

Figure 4. Recombinant Egl selectively recognizes several mRNA localization elements in vitro. $(A, B)$ In vitro translated (IVT), ${ }^{35} S$ methionine-labeled proteins, as indicated, were tested for recruitment to streptavidin/aptamer-immobilized RNAs. Images show radioactive signals. Load represents $5 \%$ of that used in each RNA-binding assay. (C) Quantification of recruitment of IVT-Egl to RNAs, normalized to the wild-type TLS. Number of independent experiments is indicated above bars; error bars represent SEM. (D) Recombinant Egl alone, Egl:BicD complex, or BicD alone, overexpressed and purified from yeast, tested for recruitment to streptavidin/ aptamer-immobilized RNAs. Images show Western blots. Load represents $10 \%$ of that used in each RNA-binding assay. (E) Quantification of specific recruitment of yeast-expressed Egl-BicD complex to RNAs (using Western blot signals), normalized to the wild-type TLS. Number of independent experiments is indicated above bars; error bars represent SEM. (F) EMSA showing the increased affinity of the yeast-expressed Egl-BicD complex for a wild-type (TLS) compared with a mutant stem-loop (TLS ${ }^{a s}$ ) (both in the context of the streptavidin aptamer). Top band is ribonucleoprotein (RNP) complex. (G) EMSA showing a higher concentration of cold TLS $S^{a s}$ than cold TLS is needed to compete equivalently (open arrowheads) with ${ }^{32} \mathrm{P}-$-labeled-TLS RNA for Egl-BicD. A $50 \mathrm{nM}$ Egl-BicD was loaded in each assay. Each RNA was linked to the streptavidin aptamer.

completely reproducible. Yeast-expressed BicD alone was not significantly retained on any of the transcripts tested (Fig. 4D), providing strong evidence that Egl is responsible for specific RNA recognition within the heteromeric complex.

Because appropriate folding of overexpressed polypeptides in a cellular environment is often assisted by incorporation into a complex with a natural binding partner (Ellis and Hartl 1999; Tan 2001), we suspect that BicD binding could provide specificity to coexpressed Egl by allowing it to adopt the appropriate confor- mation. Such a requirement for BicD may be dispensable when Egl is expressed at low levels in rabbit reticulocyte lysates, a system that is often more suitable for the folding of higher eukaryotic proteins (Ellis and Hartl 1999). Although we cannot rule out the alternative possibility that rabbit reticulocyte lysates contain BicD homologs or another cofactor that modulates the specificity of in vitro translated Egl, we judge this to be unlikely because rabbit BicD1 and BicD2 are not detectable in the lysates and because preincubating yeastexpressed Egl with unprogrammed lysates does not 
reconstitute significant specificity for localizing signals (M Dienstbier and S Bullock, unpubl.).

We next tested the behavior of the Egl-BicD complex in electrophoretic mobility shift assays (EMSA). In this independent assay, the heteromeric complex also associated with radioactive aptamer-linked TLS RNA and exhibited higher affinity for the RNA containing the wild-type element (apparent $K_{d} \sim 25 \mathrm{nM}$ ) than a nonlocalizing control (TLS ${ }^{a s}$; apparent $K_{d} \sim 75 \mathrm{nM}$ ) (Fig. 4F). Preferential recognition of a wild-type element by the Egl-BicD complex was also confirmed by competition assays, in which the association of a radioactive aptamerlinked TLS RNA with the Egl-BicD complex was competed more efficiently by a cold RNA containing the TLS than by one containing the TLS $S^{a s}$ mutant (Fig. 4G). Interestingly, the association of Egl-BicD with aptamerlinked TLS was competed very poorly by the 44-nucleotide (nt) TLS sequence alone (data not shown), suggesting that nonspecific contacts of Egl with neighboring sequences may also play a role in complex formation.

Collectively, our experiments demonstrate that Egl is an RNA-binding protein capable of direct recognition of features in multiple transcripts that are essential for asymmetric localization by dynein.

RNA-binding activity of Egl is mediated by amino acids 1-814 and is dependent on an exonuclease homology domain

As described in the introduction, Egl does not contain a canonical RNA-binding motif. We therefore delimited the RNA-binding features of Egl by producing a series of truncated versions of the protein in rabbit reticulocyte lysates and assaying their ability to bind aptamer-linked TLS or ILS RNA tethered to a streptavidin matrix (Fig. $5 \mathrm{~A}, \mathrm{~B})$. The shortest form of $\mathrm{Egl}$ that associated with RNA was amino acids 1-814, which also bound preferentially to the wild-type TLS and ILS compared with nonlocalizing controls (TLS ${ }^{U 6 C}$ and $\left.I L S^{a s}\right)$. Thus, the features in Egl that mediate direct contacts with localization signals are either spread over a large portion of Egl or are contained within a smaller region that depends on accessory sequences to be presented appropriately.

The only similarity within amino acids 1-814 of Egl to known protein motifs is found between residues 557 and 726 and the RNaseD class of $3^{\prime}-5^{\prime}$ exonuclease domain (Mach and Lehmann 1997), which in other proteins catalyzes the exonucleolytic cleavage of structured DNA or RNA (Moser et al. 1997; Shen and Loeb 2000). Removal of this homology region strongly diminished the ability of Egl to associate with RNA (Fig. 5A,B). A physiological role for this domain in RNA binding is supported by the finding that its deletion renders Egl nonfunctional in Drosophila without affecting the protein's stability or capacity to bind BicD (Navarro et al. 2004). This previous study also showed that mutating five putative catalytic amino acids in the Egl exonuclease homology region (D561, E563, D621, Y704, and D708) makes no discernible difference to the ability of Egl to function in vivo, despite each of them being critical for
A

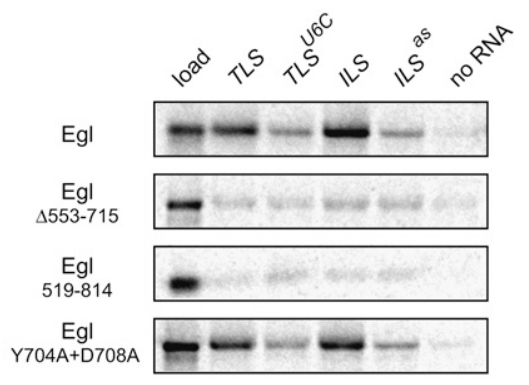

B

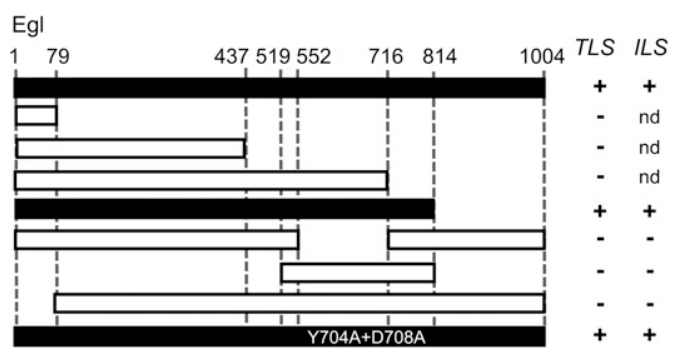

Figure 5. Egl binds RNA through amino acids 1-814 independently of putative exonuclease activity. (A) Representative examples of the recruitment of ${ }^{35} \mathrm{~S}$-methionine-labeled, in vitro translated Egl constructs to streptavidin-immobilized active (TLS and $I L S)$ and inactive (TLS $S^{U 6 C}$ and $\left.I L S^{a s}\right)$ RNA elements. (B) Summary of mapping of Egl RNA-binding features from at least two independent experiments for each construct. (+) RNA binding; (-) no/very weak RNA binding; (nd) not determined. Numbers indicate Egl amino acid position. Mutation of two residues essential for catalytic activity of canonical $3^{\prime}-5^{\prime}$ exonucleases (Y704 and D708) does not interfere with binding of full-length Egl to RNA. Equivalent molar concentrations of in vitro translated proteins were used in each experiment.

exonucleolytic activity of other proteins (Bernad et al. 1989). Consistent with these results, we found that the double mutant Y704A + D708A does not alter RNAbinding properties of Egl in vitro (Fig. 5A,B). These experiments demonstrate that essential features for RNA binding are contained within an exonuclease homology region of Egl, but are not related to classical exonuclease activity.

Efficient transport of heterologous cargoes by BicD $\Delta C$ requires the endogenous BicD CTD and Egl

The data presented above show that Egl associates with RNA and, through amino acids 1-79, with the CTD of BicD. When considered alone, these findings offer a simple explanation for the ability of MS2x6 RNA to be translocated apically when tethered to $\mathrm{BicD} \Delta \mathrm{C}$ in vivo: The requirement for the CTD and Egl is bypassed when the RNA is directly linked to the $\mathrm{N}$ terminus of BicD. However, this interpretation is not consistent with certain other observations. It has been clearly demonstrated that Egl also directly binds Dlc through a consensus light chain-binding site located between amino acids 963 and 969 (Navarro et al. 2004). A mutation in this region 
(S965L [encoded by the $e g l^{3 e}$ allele]) inhibits the binding to Dlc, but does not interfere with either the ability to form a complex with BicD in vivo (Navarro et al. 2004) or RNA-binding features (see Egl 1-814) (Fig. 5B). Despite the likely retention of a link between the BicD $\mathrm{N}$ terminus and RNA in the S965L mutant, the RNA transport process is severely compromised (Navarro et al. 2004; Bullock et al. 2006). This implies that the interaction of Egl with Dlc has an important role, which should not necessarily be overcome by artificially tethering cargo to the BicD $\mathrm{N}$ terminus.

We reasoned that because $\mathrm{BicD} \Delta \mathrm{C}$ retains the capacity to interact with other copies of BicD (Supplemental Table $1)$, its activity in the MS2 tethering assays could be mediated by binding the endogenous full-length protein, thereby allowing association with Dlc through Egl bound to the CTD. In support of this notion, the apical localization of $M S 2 x 6$ RNA by BicD $\Delta \mathrm{C}: \mathrm{CP}$ was abolished by blocking endogenous BicD activity through injection of the 1B11 antibody (Suter and Steward 1991) that recognizes a C-terminal epitope not contained in the fusion protein (Fig. 6A,B). We also found that in BicD $\Delta \mathrm{C}: \mathrm{CP}$ embryos, MS2x6 RNA recruited Egl, and that apical

A

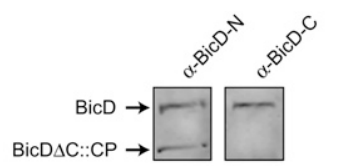

B
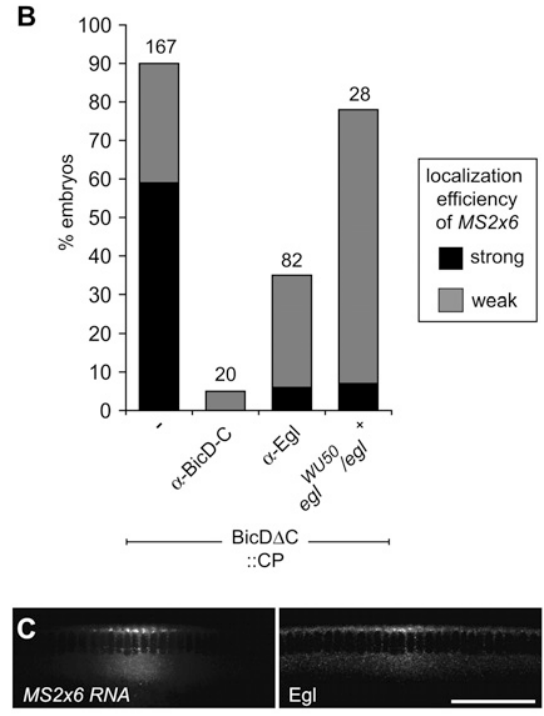

$B i c D \triangle C:: C P$

Figure 6. The localization driven by $\mathrm{BicD} \Delta \mathrm{C}: \mathrm{CP}$ is dependent on endogenous BicD and Egl. $(A)$ The $\alpha$-BicD-C antibody $1 \mathrm{~B} 11$ does not recognize the truncated BicD in extracts of BicD $\Delta C:: C P$ embryos. The expected position of $\mathrm{BicD} \Delta \mathrm{C}: \mathrm{CP}$ is marked by the $\alpha$-BicD-N antibody $4 \mathrm{C} 2$, which binds an epitope between amino acids 1 and 543. (B) Localization of MS2x6 RNA by BicD $\Delta \mathrm{C}:$ :CP is strongly reduced by preinjection of $\alpha-\mathrm{BicD}-\mathrm{C}, \alpha-\mathrm{Egl}$, or by halving egl gene dosage. The data for MS2x6 localization in uninjected BicD $\Delta \mathrm{C}:: \mathrm{CP}$ embryos is reproduced from Figure 1A for comparison. (C) Recruitment of Egl to apically enriched MS2x6 RNA in BicD $\Delta \mathrm{C}:: \mathrm{CP}$ embryos. Bar, $50 \mu \mathrm{m}$. enrichment of the RNA was inhibited by interfering with Egl function using a specific blocking antibody or by halving gene dosage (Fig. 6B,C).

Thus, at least in flies, the N-terminal two-thirds of the protein is not sufficient for BicD-mediated delivery of cargoes to the minus ends of microtubules. Instead, its potent ability to promote apical transport is through association with endogenous BicD-containing transport complexes, the bulk of which presumably undergo net apical movement. These endogenous complexes include important factors that associate via the BicD CTD, such as Egl and Dlc.

\section{Discussion}

Egl is responsible for direct recognition of localization signals from multiple different $m R N A s$

Because of difficulties in finding shared features between dynein-dependent localization signals in different transcripts, it was not known whether dedicated factors are responsible for recognizing each of these elements. This uncertainty has severely restricted the ability to generalize conclusions from studies of localization mechanisms of individual transcripts. Our work demonstrates that the same protein, Egl, is capable of specifically contacting minus-end-directed localization signals from multiple different transcripts. This conclusion is supported by the findings that (1) Egl and BicD are the only factors visibly enriched from embryonic extracts on all four localizing elements tested relative to a number of nonlocalizing controls, (2) Egl function in Drosophila is required for BicD-mediated transport of mRNAs and not other cargoes tested, (3) the majority of Egl, but not BicD, in cell extracts is found in a complex whose size is sensitive to Rnase treatment, and (4) recombinant Egl, but not BicD, binds RNA in vitro and is capable of discriminating between active apical localization signals and those containing subtle inactivating mutations.

In addition to the four elements tested in this study, Egl is also likely to associate directly with other mRNA localization signals because $b c d, f t z$, and $w g$ recruit Egl in vivo and depend on its function for minus-end-directed transport (Supplemental Fig. 4; Bullock and Ish-Horowicz 2001; Bullock et al. 2004). Indeed, Egl binding may be the major, and perhaps only, specific determinant of the activity of an apical localization signal, as all three subtle inactivating mutations that we tested inhibit association of Egl from embryonic extracts $\left(T L S^{\Delta b u b}, T L S^{U 6 C}\right.$, and $\left.h S L 1^{C 15 G}\right)$, and a fourth inactive point mutant (bcdSLV $4496 G-U)$ (Macdonald and Kerr 1997) prevents recruitment of Egl to bcd injected into embryos (Bullock and Ish-Horowicz 2001). Presumably, despite differences in primary sequence composition, all of the characterized localization elements contain cryptic structural features that are recognized by Egl. Elucidating the structural basis of this recognition event will be the goal of future long-term studies.

Interestingly, Egl exhibits some affinity for inactive localization elements when expressed recombinantly, as 
well as in embryonic extracts. Egl may well exhibit greater selectivity for active signals in the appropriate in vivo context. This could be because the composition of our in vitro binding buffers is suboptimal. Alternatively, the incorporation of mRNAs into oligomeric particles within the cell (Wilkie and Davis 2001; Bullock et al. 2006) may give rise to cooperative interactions between individual Egl and BicD complexes, thereby increasing cargo specificity. Nonetheless, an inherent degree of promiscuity by Egl in vivo would fit with our previous finding that its overexpression in embryos is sufficient to target a small amount of an endogenous nonlocalizing transcript population to the apical cytoplasm (Bullock et al. 2006) and could also be the basis of repeated emergence of apical localization signals during dipteran evolution (Bullock et al. 2004).

The mRNA elements that direct apical transport in the blastoderm embryo are also capable of mediating localization of transcripts toward the minus ends of microtubules during oogenesis (Bullock and Ish-Horowicz 2001; Cohen et al. 2005; Van De Bor et al. 2005). It is therefore very likely that direct binding of Egl to these stem-loops is also functionally significant during these stages. Indeed, Egl and BicD have been shown to be components of motor complexes that transport grk from the nurse cells into the oocyte (Clark et al. 2007). Interestingly, within the oocyte the $h$ and $K 10$ elements are involved in localization to the anterior cortex (Serano and Cohen 1995; Bullock and Ish-Horowicz 2001), whereas those in grk and the I factor are also sufficient for translocation from the anterior to the dorso-anterior corner (Van De Bor et al. 2005). Dorsalward movement is presumably due to the binding of the ILS and GLS to oocyte-specific factors in addition to Egl, either sequentially or simultaneously, or by modulating the mode of Egl binding.

\section{Linkage of $m R N A$ s to the motor complex and the regulation of transport}

It has previously been shown that $\mathrm{Egl}$ and BicD are in a complex together in vivo (Mach and Lehmann 1997). Our data shows for the first time that Egl, through its $\mathrm{N}$-terminal 79 amino acids, directly interacts with BicD. In addition, Egl also binds Dlc through a consensus light chain-binding site between amino acids 963 and 969 (Navarro et al. 2004). BicD is able to recruit the dynein/dynactin complex (Hoogenraad et al. 2003) and Dlc associates with other dynein subunits (Bell et al. 1979). Thus, together with our evidence for Egl RNA binding through amino acids $1-814$, it is now possible to build a working model of a complete link between minusend-directed mRNA signals and microtubules for the first time (Fig. 7).

Egl, BicD, and mRNA elements do not appear to be obligatory for particle assembly or bidirectional mRNA motility (Bullock et al. 2006). Instead, they are likely to be essential parts of a cassette that up-regulates minus-enddirected movement of a generic bidirectional mRNA transport complex. Other RNA-binding factors presum-

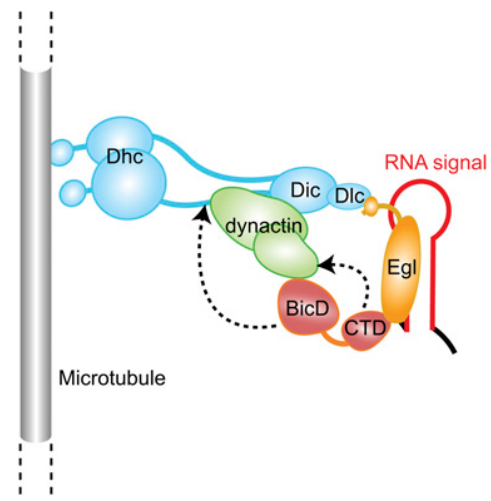

Figure 7. Model for a complete link between minus-enddirected mRNA localization signals and microtubules. See the text for details. The arrows show putative interactions of $\mathrm{BicD}$ with the dynein/dynactin complex (Hoogenraad et al. 2001, 2003). For simplicity, single copies of the mRNA signal, Egl and BicD, are shown, but mRNAs can be transported as particles (Delanoue et al. 2007) and dimerization or oligomerization of $\mathrm{BicD}$ and Egl may be significant for achieving a transportcompetent complex. In addition to the factors shown, generic RNA-binding proteins and a dedicated plus-end-directed motor could also be involved. Dlc, Dic, and Dhc are components of the dynein complex implicated in the mRNA transport complex to date.

ably package both localizing and nonlocalizing RNAs and provide additional links to motors.

Within the minus-end regulatory cassette, the role of $\mathrm{Egl}$ is probably to recruit both BicD and Dlc to the mRNA to ensure efficient targeting of transcripts to the minus ends of microtubules. The presence of both Egl-interacting partners might be required for the stability of the motor complex. Alternatively, our previous observations of the effects of altering protein concentrations on mRNA transport are consistent with Egl-Dlc and Egl-BicD interactions regulating different aspects of motility of the bidirectional motor complex: processivity and switching behavior, respectively (Bullock et al. 2006). Like Egl, Rab6 is able to associate with both BicD and a Dlc (Wanschers et al. 2008). Association with both BicD and Dlc may therefore be a common strategy used by cargo adaptors to ensure efficient minus-end-directed transport.

\section{General implications for mechanisms of microtubule-based cargo transport}

Binding of both Egl and Rab6 to BicD is sensitive to the same amino acid substitution in the CTD. Egl and Rab6 recognize localizing mRNAs and Golgi vesicles, respectively, raising the possibility that BicD functions in the transport of different cargoes through mutually exclusive association of the CTD with cargo-specific adaptors. We found that relatively subtle overexpression of Egl not only augments BicD-dependent apical mRNA transport (Bullock et al. 2006), but also antagonizes BicD function in lipid droplet motility. This implies that, through competition for the BicD CTD, the pathways 
for microtubule-based transport of different cargoes can be finely balanced. Alteration of the availability of adaptors for BicD is therefore a potentially effective strategy for regulating net sorting of cargoes.

Our experiments involving the tethering of cargoes to BicD domains also shed light on potential general mechanisms of dynein-based cargo transport. As is the case for mammalian BicD (Hoogenraad et al. 2003), removal of the CTD of the Drosophila protein stimulates transport by dynein. This situation presumably mimics a version of the full-length protein bound to a cargo adaptor in which an autoinhibitory effect of the $\mathrm{C}$ terminus is negated (Hoogenraad et al. 2003). The $\mathrm{N}$ terminus of BicD can efficiently capture dynein/dynactin components from cell extracts (Hoogenraad et al. 2003), suggesting that this interaction could be entirely sufficient for productive transport. However, our results indicate that, at least in Drosophila, the capacity of BicD $\Delta \mathrm{C}$ to mediate net movement of tethered cargoes is dependent on its association with endogenous BicD transport complexes. Such a scenario was not directly tested in the previous mammalian cell assays (Hoogenraad et al. 2003).

In the case of minus-end-directed mRNA transport in flies, the CTD appears to provide an essential link, through Egl, to Dlc. In addition, the CTD can associate with the dynamitin subunit of dynactin (Hoogenraad et al. 2001). The significance of this interaction was not clear in light of a model in which only the N-terminal sequences of BicD are important for transport by dynein. Our finding that the CTD is needed in trans for the activity of $\mathrm{BicD} \Delta \mathrm{C}$ revives the possibility that the dynamitin interaction is functionally important (Fig. 7).

The ability of BicD $\Delta \mathrm{C}:: \mathrm{CP}$, but not BicD::CP, to target heterologous cargoes apically is likely to reflect a role for the CTD in inhibiting association with other copies of $\mathrm{BicD}$. Consistent with this notion, $\mathrm{BicD} \Delta \mathrm{C}:: \mathrm{CP}$ accumulates in large, apically enriched puncta, whereas the fulllength protein fused to the coat protein fails to form discrete particles and has a uniform distribution (Fig. 1A). Together with the observation that $\mathrm{BicD}$ is able to associate with other copies of itself in vivo $/ \mathrm{Oh}$ et al. 2000), these results imply that dimerization or oligomerization of BicD could be an important step in the activation of transport by cargo binding. Future experiments will be aimed at determining the copy number of components of the transport complex in the presence and absence of a bound consignment.

\section{Materials and methods}

Additional Materials and Methods can be found in the Supplemental Material.

\section{Egl numbering}

All numbering of Egl is according to the predicted protein Q7YU43, which contains an additional $11 \mathrm{~N}$-terminal amino acids to those contained in P92030/U86404.2 (Navarro et al. 2004). These amino acids are likely to be functionally significant as this region is conserved in insect Egl proteins.

\section{Streptavidin-based RNA affinity purifications}

Previously (Bullock et al. 2006), 700-nt regions of localizing and nonlocalizing RNAs were appended to the streptavidin-binding aptamer (Srisawat and Engelke 2001). These fusion transcripts were immobilized to a streptavidin-agarose matrix and used to capture proteins from embryonic extracts selective for localizing RNAs, which included Egl and BicD, as judged by Western blotting. The abundance of nonspecific binding proteins in these experiments precluded identification of specific factors by mass spectrometry. We subsequently found that the capture on localizing RNAs of Egl and BicD relative to nonspecific binding proteins can be improved markedly by appending only the minimal localization elements (44-63 nt) to the aptamers, extensive post-binding washes, and the use of a biotin elution step to enrich for proteins associated with RNA relative to those associated with the matrix.

Minimal localization elements and mutants were cloned into the XmaI site of the pTRAP version 5 vector (Cytostore, Inc.) using complementary oligonucleotides, followed by sequencing to confirm their orientation and integrity. Uncapped RNAs, with two copies of the streptavidin-binding aptamer at the $5^{\prime}$, were generated by in vitro transcription (MEGAshortscript kit, Ambion) from BamHI-linearized plasmids and purified from unincorporated nucleotides and salts using NucAway spins columns (Ambion). In control experiments, we determined that each localizing and nonlocalizing aptamer fusion RNA bound equivalently to the streptavidin matrix.

Extracts from 0-10 h embryos were produced as described (Bullock et al. 2006) in Drosophila extraction buffer (DXB: 30 $\mathrm{mM}$ Hepes at $\mathrm{pH} 7.3,50 \mathrm{mM} \mathrm{KCl}, 2.5 \mathrm{mM} \mathrm{MgCl} 2,250 \mathrm{mM}$ sucrose, $1 \mathrm{mM}$ DTT, $2 \times$ Complete [EDTA-free] protease inhibitors [Roche]), and precleared with a $20-\mu \mathrm{L}$ packed volume of PBS-washed streptavidin agarose beads (Invitrogen) per $200 \mu \mathrm{L}$ of extract by rotating for $1-2 \mathrm{~h}$ at $4^{\circ} \mathrm{C}$. Beads were centrifuged at $1000 \mathrm{~g}$ for $2 \mathrm{~min}$, and the supernatant collected. In the meantime, PBS-washed streptavidin agarose beads were washed once in buffer A $\left(30 \mathrm{mM}\right.$ Hepes at $\mathrm{pH} 7.3,2.5 \mathrm{mM} \mathrm{MgCl}_{2}, 160 \mathrm{mM} \mathrm{KCl}$, $0.1 \%$ Triton X-100, $10 \%$ glycerol, $1 \mathrm{mM} \mathrm{DTT}, 1 \times$ Complete [EDTA-free] protease inhibitors) and resuspended in a slurry with $5 \mathrm{vol}$ of buffer A. For each experiment, $20 \mu \mathrm{g}$ of aptamer-fused RNA, and $20 \mathrm{U}$ of RNase inhibitor was added to $100 \mu \mathrm{L}$ of bead slurry and incubated at $4^{\circ} \mathrm{C}$ while shaking on a Thermomixer (Eppendorf) for 1-2 h. Beads and associated RNA were collected by centrifugation at $1000 \mathrm{~g}$ for $2 \mathrm{~min}$ and incubated with $200 \mu \mathrm{L}$ of precleared extract containing $20 \mathrm{U}$ of RNase inhibitor at $4^{\circ} \mathrm{C}$, also while shaking on a Thermomixer for $1-2 \mathrm{~h}$. Beads were then washed eight to 10 times in buffer A (two rinses followed by six to eight 10-min incubations while rotating) and RNA:protein complexes eluted by incubating with biotin to a final concentration of $10 \mathrm{mM}$ for $2 \mathrm{~h}$ at $4^{\circ} \mathrm{C}$.

Essentially the same procedure was used for in vitro translated $\left({ }^{35}\right.$ S-methionine labeled) and recombinant proteins, except that streptavidin-linked magnetic dynabeads (Invitrogen) were used instead of streptavidin-agarose beads $(2 \mu \mathrm{g}$ of RNA was bound to $50 \mu \mathrm{L}$ of Dynabeads slurry and five to six washes were performed using a magnetic rack on ice). The concentrations of recombinant proteins and protein complexes in $200 \mu \mathrm{L}$ of DXB buffer were adjusted to $10 \mathrm{nM}$. The volume of reticulocyte lysate reaction inputted into RNA-binding assays was adjusted to give equivalent amounts of each synthesized protein, determined by PhosphorImaging. Based on the manufacturer's information on typical synthesis efficiency, the final concentration of these proteins in the assay is $<1 \mathrm{nM}$. In all experiments, we confirmed that the ratio of localizing and nonlocalizing control RNAs was unaltered through the procedure by 
visualizing eluted RNA on ethidium bromide-stained 6\% TBU gels (Invitrogen).

\section{Recombinant protein expression and purification}

PCR-amplified Egl and BicD coding sequences were cloned into pYTEV vectors (kindly provided by A.-M. van Roon, E. Obayashi, and K. Nagai [LMB]) providing either a C-terminal Calmodulinbinding peptide (CBP) or 8xHis tag, as well as flanking regulatory sequences that allow induction by galactose. Following sequencing to confirm the integrity of $\mathrm{Egl}$ and $\mathrm{BicD}$, these sequences were transferred into the pRS420 series of high-copy-number yeast vectors (Christianson et al. 1992) containing the TRP1 (Egl$\mathrm{CBP}$ and BicD-CBP) and URA3 (BicD-His) selective markers. The S. cerevisiae strain BCY123, doubly transformed with expression vectors with TRP1 and URA3 selectable markers (empty vector provided one marker in the case of single protein expression), was grown in YM4 selective medium $10.8 \% \mathrm{w} / \mathrm{v}$ yeast nitrogen base, $1.1 \% \mathrm{w} / \mathrm{v}$ casamino acids, $0.0055 \% \mathrm{w} / \mathrm{v}$ adenine, $0.0055 \% \mathrm{w} / \mathrm{v}$ tyrosine) supplemented with $2 \%$ raffinose at $30^{\circ} \mathrm{C}$ to OD600 1.0. Protein expression was then induced by $2 \%$ galactose for $15-20 \mathrm{~h}$ at $30^{\circ} \mathrm{C}$. Cells were harvested by centrifugation, followed by washing and resuspension in the same volume of cold 2xCAL250 buffer (20\% glycerol, $100 \mathrm{mM}$ Tris- $\mathrm{Cl}$ at $\mathrm{pH} 8.0,500 \mathrm{mM} \mathrm{NaCl}$, $2 \mathrm{mM}$ MgOAc, $2 \mathrm{mM}$ imidazole, $4 \mathrm{mM} \mathrm{CaCl}_{2}, 0.2 \% \mathrm{NP} 40$ ). Cells were lysed by five 20 -sec bursts on a FastPrep bead-beater with $1 / 3$ vol of $500-\mu \mathrm{m}$ acid-washed glass beads (Sigma), with 5 -min intervals on ice, and clarified by centrifugation at $17,000 g$

CBP-tagged Egl or BicD was purified from lysates by incubating with calmodulin-sepharose (GE Healthcare) overnight at $4^{\circ} \mathrm{C}$, followed by four to five washes in $1 \times$ CAL250 buffer. Protein was then eluted in fractions on a column by $1 \times$ CAL250E buffer $(1 \times$ CAL250 with $2 \mathrm{mM}$ EGTA instead of $\mathrm{CaCl}_{2}$ ), fractions analyzed on SDS-PAGE, and protein concentration quantified by Bradford assays (Thermo Scientific). For coexpression of the Egl-BicD complex, His-tagged BicD was copurified with CBP-tagged Egl using the same single-step procedure for purification of CBP; additional purification steps were not routinely performed on the complex, as this led to a large reduction of yield and no significant improvement in purity. The typical yield of purified proteins was $\sim 0.1-0.2 \mathrm{mg} / \mathrm{L}$ culture.

\section{EMSA}

In vitro transcribed, aptamer-linked TLS or TLS ${ }^{a s}$ RNA was 5'end-labeled with ${ }^{32} \mathrm{P}$-ATP using T4 polynucleotide kinase (New England Biolabs), followed by phenol-chloroform extraction and removal of unincorporated nucleotides by a NucAway spin column (Ambion). A serial dilution of recombinant Egl-BicD protein complex in DXB buffer was incubated with $1 \mathrm{nM}{ }^{32} \mathrm{P}$ labeled RNA in a $10-\mu \mathrm{L}$ reaction for $30 \mathrm{~min}$ on ice. Samples were loaded on a $6 \%$ DNA retardation gel (Invitrogen) and electrophoresed for $1 \mathrm{~h}$ on ice in $0.5 \times \mathrm{TBE}$ buffer. The gel was dried and analyzed by phosphorimaging. Apparent $K_{d}$ was determined by a linear fit of a double reciprocal plot ( $1 /$ fraction bound vs. $1 /$ protein concentration).

EMSA competition assays were based on standard protocols (Black et al. 1998). A $50 \mathrm{nM}$ Egl-BicD complex was preincubated with a serial dilution of aptamer-linked unlabeled TLS or TLS $S^{a s}$ RNA for $30 \mathrm{~min}$ on ice before adding $1 \mathrm{nM}^{32} \mathrm{P}$-labeled aptamerfused TLS. Samples were then incubated and analyzed on the gel as above in order to compare the concentrations of unlabeled RNAs that compete equivalently with the radioactive RNP complex.

\section{Acknowledgments}

We are grateful to C. Dix for improvements to the RNA pulldown protocol; G. Gatto for assistance with making constructs; Y. Liu and X.-Y. Zhang for advice on protein purification and gel filtration, respectively; I. Ringel and D. Ish-Horowicz for sharing unpublished results; P. Lukavsky, A. Newman, and members of the Bullock laboratory for discussions and/or reading the manuscript; R. Lehmann, R. Long, K. Nagai, C. Navarro, E. Obayashi, J. Mueller, P. Stockley, A.-M. van Roon, the Developmental Studies Hybridoma Bank, and Drosophila Genome Resource Center for reagents; and F. Begum and S.-Y. Peak Chu for mass spectrometry. This work was funded by the Medical Research Council. M.D. is a recipient of an LMB Newton European scholarship, and S.B. is a Lister Institute Prize Fellow.

\section{References}

Bell CW, Fronk E, Gibbons IR. 1979. Polypeptide subunits of dynein 1 from sea urchin sperm flagella. I Supramol Struct 11: 311-317.

Bernad A, Blanco L, Lazaro JM, Martin G, Salas M. 1989. A conserved $3^{\prime}-5^{\prime}$ exonuclease active site in prokaryotic and eukaryotic DNA polymerases. Cell 59: 219-228.

Black DL, Chan R, Min H, Wang J, Bell L. 1998. The electrophoretic mobility shift assay for RNA binding proteins. In RNA:protein interactions: A practical approach (ed. CWJ Smith), pp. 109-136. Oxford University Press, Oxford, UK.

Bullock SL, Ish-Horowicz D. 2001. Conserved signals and machinery for RNA transport in Drosophila oogenesis and embryogenesis. Nature 414: 611-616.

Bullock SL, Zicha D, Ish-Horowicz D. 2003. The Drosophila hairy RNA localization signal modulates the kinetics of cytoplasmic mRNA transport. EMBO J 22: 2484-2494.

Bullock SL, Stauber M, Prell A, Hughes JR, Ish-Horowicz D, Schmidt-Ott U. 2004. Differential cytoplasmic mRNA localisation adjusts pair-rule transcription factor activity to cytoarchitecture in dipteran evolution. Development 131: 4251-4261.

Bullock SL, Nicol A, Gross SP, Zicha D. 2006. Guidance of bidirectional motor complexes by mRNA cargoes through control of dynein number and activity. Curr Biol 16: 1447-1452.

Christianson TW, Sikorski RS, Dante M, Shero JH, Hieter P. 1992. Multifunctional yeast high-copy-number shuttle vectors. Gene 110: 119-122.

Clark A, Meignin C, Davis I. 2007. A Dynein-dependent shortcut rapidly delivers axis determination transcripts into the Drosophila oocyte. Development 134: 1955-1965.

Claussen M, Suter B. 2005. BicD-dependent localization processes: From Drosophilia development to human cell biology. Ann Anat 187: 539-553.

Cohen RS, Zhang S, Dollar GL. 2005. The positional, structural, and sequence requirements of the Drosophila TLS RNA localization element. RNA 11: 1017-1029.

Coutelis JB, Ephrussi A. 2007. Rab6 mediates membrane organization and determinant localization during Drosophila oogenesis. Development 134: 1419-1430.

Delanoue R, Herpers B, Soetaert J, Davis I, Rabouille C. 2007. Drosophila Squid/hnRNP helps Dynein switch from a gurken mRNA transport motor to an ultrastructural static anchor in sponge bodies. Dev Cell 13: 523-538.

dos Santos G, Simmonds AJ, Krause HM. 2008. A stem-loop structure in the wingless transcript defines a consensus motif for apical RNA transport. Development 135: 133-143.

Ellis RJ, Hartl FU. 1999. Principles of protein folding in the cellular environment. Curr Opin Struct Biol 9: 102-110. 
Gonsalvez GB, Urbinati CR, Long RM. 2005. RNA localization in yeast: Moving towards a mechanism. Biol Cell 97: 7586.

Hoogenraad CC, Akhmanova A, Howell SA, Dortland BR, De Zeeuw CI, Willemsen R, Visser P, Grosveld F, Galjart N. 2001. Mammalian Golgi-associated Bicaudal-D2 functions in the dynein-dynactin pathway by interacting with these complexes. EMBO I 20: 4041-4054.

Hoogenraad CC, Wulf P, Schiefermeier N, Stepanova T, Galjart N, Small JV, Grosveld F, de Zeeuw CI, Akhmanova A. 2003. Bicaudal D induces selective dynein-mediated microtubule minus end-directed transport. EMBO J 22: 6004-6015.

Hughes JR, Bullock SL, Ish-Horowicz D. 2004. Inscuteable mRNA localization is dynein-dependent and regulates apicobasal polarity and spindle length in Drosophila neuroblasts. Curr Biol 14: 1950-1956.

Januschke J, Nicolas E, Compagnon J, Formstecher E, Goud B, Guichet A. 2007. Rab6 and the secretory pathway affect oocyte polarity in Drosophila. Development 134: 3419-3425.

Larsen KS, Xu J, Cermelli S, Shu Z, Gross SP. 2008. BicaudalD actively regulates microtubule motor activity in lipid droplet transport. PLoS One 3: e3763. doi: 10.1371/journal.pone. 0003763.

Macdonald PM, Kerr K. 1997. Redundant RNA recognition events in bicoid mRNA localization. RNA 3: 1413-1420.

Macdonald PM, Kerr K. 1998. Mutational analysis of an RNA recognition element that mediates localization of bicoid mRNA. Mol Cell Biol 18: 3788-3795.

Mach JM, Lehmann R. 1997. An Egalitarian-BicaudalD complex is essential for oocyte specification and axis determination in Drosophila. Genes \& Dev 11: 423-435.

Mansfield JH, Wilhelm JE, Hazelrigg T. 2002. Ypsilon Schachtel, a Drosophila Y-box protein, acts antagonistically to Orb in the oskar mRNA localization and translation pathway. Development 129: 197-209.

Martin KC, Ephrussi A. 2009. mRNA localization: Gene expression in the spatial dimension. Cell 136: 719-730.

Matanis T, Akhmanova A, Wulf P, Del Nery E, Weide T, Stepanova T, Galjart N, Grosveld F, Goud B, De Zeeuw CI, et al. 2002. Bicaudal-D regulates COPI-independent Golgi-ER transport by recruiting the dynein-dynactin motor complex. Nat Cell Biol 4: 986-992.

Moorhead AR, Rzomp KA, Scidmore MA. 2007. The Rab6 effector Bicaudal D1 associates with Chlamydia trachomatis inclusions in a biovar-specific manner. Infect Immun 75: 781-791.

Moser MJ, Holley WR, Chatterjee A, Mian IS. 1997. The proofreading domain of Escherichia coli DNA polymerase I and other DNA and/or RNA exonuclease domains. Nucleic Acids Res 25: 5110-5118.

Navarro C, Puthalakath H, Adams JM, Strasser A, Lehmann R. 2004. Egalitarian binds dynein light chain to establish oocyte polarity and maintain oocyte fate. Nat Cell Biol 6: 427-435.

Oh J, Baksa K, Steward R. 2000. Functional domains of the Drosophila Bicaudal-D protein. Genetics 154: 713-724.

Pearson J, Gonzalez-Reyes A. 2004. Egalitarian and the case of the missing link. Nat Cell Biol 6: 381-383.

Purcell K, Artavanis-Tsakonas S. 1999. The developmental role of warthog, the notch modifier encoding Drab6. I Cell Biol 146: 731-740.

Ran B, Bopp R, Suter B. 1994. Null alleles reveal novel requirements for Bic-D during Drosophila oogenesis and zygotic development. Development 120: 1233-1242.

Serano TL, Cohen RS. 1995. A small predicted stem-loop structure mediates oocyte localization of Drosophila K10 mRNA. Development 121: 3809-3818.
Shen JC, Loeb LA. 2000. Werner syndrome exonuclease catalyzes structure-dependent degradation of DNA. Nucleic Acids Res 28: 3260-3268.

Short B, Preisinger C, Schaletzky J, Kopajtich R, Barr FA. 2002. The Rab6 GTPase regulates recruitment of the dynactin complex to Golgi membranes. Curr Biol 12: 1792-1795.

Snee MJ, Arn EA, Bullock SL, Macdonald PM. 2005. Recognition of the bed mRNA localization signal in Drosophila embryos and ovaries. Mol Cell Biol 25: 1501-1510.

Srisawat C, Engelke DR. 2001. Streptavidin aptamers: Affinity tags for the study of RNAs and ribonucleoproteins. RNA 7: 632-641.

St Johnston D. 2005. Moving messages: The intracellular localization of mRNAs. Nat Rev Mol Cell Biol 6: 363-375.

Suter B, Steward R. 1991. Requirement for phosphorylation and localization of the Bicaudal-D protein in Drosophila oocyte differentiation. Cell 67: 917-926.

Swan A, Nguyen T, Suter B. 1999. Drosophila Lissencephaly-1 functions with Bic-D and dynein in oocyte determination and nuclear positioning. Nat Cell Biol 1: 444-449.

Tan S. 2001. A modular polycistronic expression system for overexpressing protein complexes in Escherichia coli. Protein Expr Purif 21: 224-234.

Tekotte H, Davis I. 2002. Intracellular mRNA localization: Motors move messages. Trends Genet 18: 636-642.

Valegard K, Murray JB, Stonehouse NJ, van den Worm S, Stockley PG, Liljas L. 1997. The three-dimensional structures of two complexes between recombinant MS2 capsids and RNA operator fragments reveal sequence-specific protein-RNA interactions. I Mol Biol 270: 724-738.

Van de Bor V, Davis I. 2004. mRNA localisation gets more complex. Curr Opin Cell Biol 16: 300-307.

Van De Bor V, Hartswood E, Jones C, Finnegan D, Davis I. 2005. gurken and the I factor retrotransposon RNAs share common localization signals and machinery. Dev Cell 9: 51-62.

Vendra G, Hamilton RS, Davis I. 2007. Dynactin suppresses the retrograde movement of apically localized mRNA in Drosophila blastoderm embryos. RNA 13: 1860-1867.

Wanschers B, van de Vorstenbosch R, Wijers M, Wieringa B, King SM, Fransen J. 2008. Rab6 family proteins interact with the dynein light chain protein DYNLRB1. Cell Motil Cytoskeleton 65: 183-196.

Welte MA, Gross SP, Postner M, Block SM, Wieschaus EF. 1998. Developmental regulation of vesicle transport in Drosophila embryos: Forces and kinetics. Cell 92: 547-557.

Whited JL, Cassell A, Brouillette M, Garrity PA. 2004. Dynactin is required to maintain nuclear position within postmitotic Drosophila photoreceptor neurons. Development 131: 46774686.

Wilkie GS, Davis I. 2001. Drosophila wingless and pair-rule transcripts localize apically by dynein-mediated transport of RNA particles. Cell 105: 209-219. 


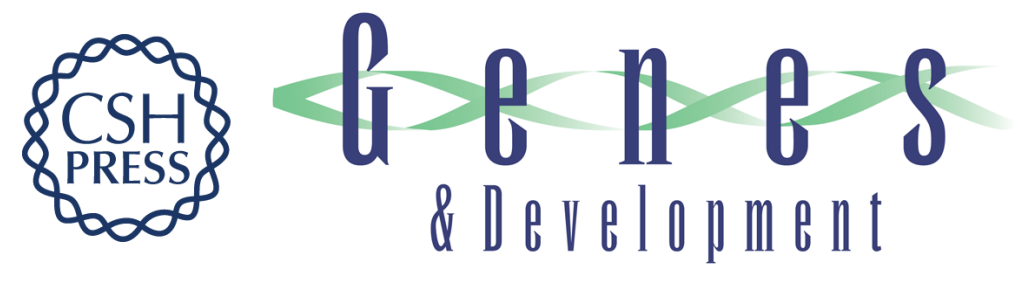

\section{Egalitarian is a selective RNA-binding protein linking mRNA localization signals to the dynein motor}

Martin Dienstbier, Florian Boehl, Xuan Li, et al.

Genes Dev. 2009, 23: originally published online June 10, 2009

Access the most recent version at doi:10.1101/gad.531009

\section{Supplemental http://genesdev.cshlp.org/content/suppl/2009/06/11/gad.531009.DC1 \\ Material}

$\begin{array}{ll}\text { Related Content } & \begin{array}{l}\text { Egalitarian recruitment of localized mRNAs } \\ \text { Dmitry Nashchekin and Daniel St Johnston }\end{array}\end{array}$

Genes Dev. July, 2009 23: 1475-1480

References This article cites 51 articles, 21 of which can be accessed free at:

http://genesdev.cshlp.org/content/23/13/1546.full.html\#ref-list-1

Articles cited in:

http://genesdev.cshlp.org/content/23/13/1546.full.html\#related-urls

\section{License}

Email Alerting

Service

Receive free email alerts when new articles cite this article - sign up in the box at the top right corner of the article or click here.

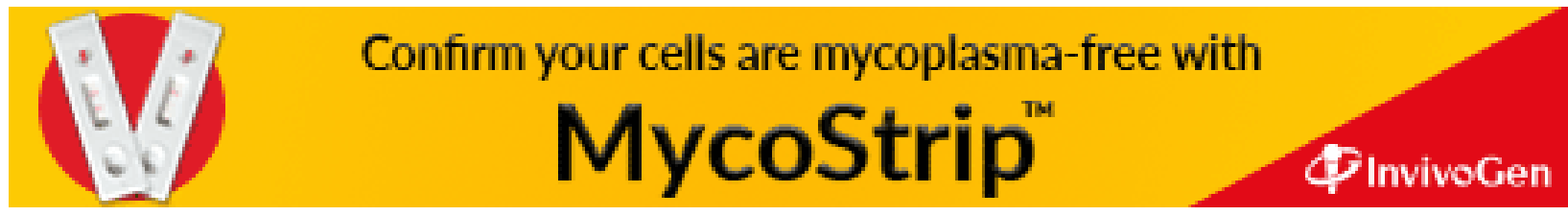

